\title{
Management of Orthostatic Hypotension in Parkinson's Disease
}

\author{
Alessandra Fanciulli ${ }^{\mathrm{a}, *}$, Fabian Leys ${ }^{\mathrm{a}}$, Cristian Falup-Pecurariu ${ }^{\mathrm{b}}$, Roland Thijs $\mathrm{s}^{\mathrm{c}, \mathrm{d}}$ \\ and Gregor K. Wenning ${ }^{\mathrm{a}}$ \\ ${ }^{a}$ Department of Neurology, Medical University of Innsbruck - Innsbruck, Austria \\ ${ }^{\mathrm{b}}$ Department of Neurology, Transilvania University, Faculty of Medicine - Brasov, Romania \\ ${ }^{\mathrm{c}}$ Department of Neurology, Leiden University Medical Centre, Leiden, The Netherlands \\ ${ }^{\mathrm{d}}$ Stichting Epilepsie Instellingen Nederland (SEIN), Heemstede, The Netherlands
}

Accepted 22 June 2020

\begin{abstract}
Orthostatic hypotension $(\mathrm{OH})$ is a common non-motor feature of Parkinson's disease that may cause unexplained falls, syncope, lightheadedness, cognitive impairment, dyspnea, fatigue, blurred vision, shoulder, neck, or low-back pain upon standing. Blood pressure (BP) measurements supine and after 3 minutes upon standing screen for $\mathrm{OH}$ at bedside. The medical history and cardiovascular autonomic function tests ultimately distinguish neurogenic $\mathrm{OH}$, which is due to impaired sympathetic nerve activity, from non-neurogenic causes of $\mathrm{OH}$, such as hypovolemia and $\mathrm{BP}$ lowering drugs. The correction of non-neurogenic causes and exacerbating factors, lifestyle changes and non-pharmacological measures are the cornerstone of $\mathrm{OH}$ treatment. If these measures fail, pharmacological interventions (sympathomimetic agents and/or fludrocortisone) should be introduced stepwise depending on the severity of symptoms. About 50\% of patients with neurogenic $\mathrm{OH}$ also suffer from supine and nocturnal hypertension, which should be monitored for with in-office, home and $24 \mathrm{~h}$-ambulatory BP measurements. Behavioral measures help prevent supine hypertension, which is eventually treated with non-pharmacological measures and bedtime administration of short-acting anti-hypertensive drugs in severe cases. If left untreated, OH impacts on activity of daily living and increases the risk of syncope and falls. Supine hypertension is asymptomatic, but often limits an effective treatment of $\mathrm{OH}$, increases the risk of hypertensive emergencies and, combined with $\mathrm{OH}$, facilitates end-organ damage. A timely management of both $\mathrm{OH}$ and supine hypertension ameliorates quality of life and prevents short and long-term complications in patients with Parkinson's disease.
\end{abstract}

Keywords: Parkinson's disease, orthostatic hypotension, post-prandial hypotension, supine hypertension, nocturnal hypertension

\section{INTRODUCTION}

Orthostatic hypotension $(\mathrm{OH})$ may affect every third patient with Parkinson's disease throughout the disease course [1-5].

$\mathrm{OH}$ manifests with syncope, unexplained falls, lightheadedness, cognitive impairment, blurred

\footnotetext{
${ }^{*}$ Correspondence to: Alessandra Fanciulli, MD, PhD, Department of Neurology, Medical University of Innsbruck, Anichstraße 35, A-6020 Innsbruck, Austria. Tel.: +43 512504 83238; E-mail: alessandra.fanciulli@i-med.ac.at.
}

vision, dyspnea, fatigue, shoulder, neck, or low-back pain, which develop upon standing and recover by lying down [6]. In some patients, $\mathrm{OH}$ may remain asymptomatic, depending both on how low the blood pressure (BP) falls upon standing and individual adaptive cerebral autoregulatory mechanisms $[7,8]$.

In $\mathrm{PD}, \mathrm{OH}$ is mostly neurogenic, i.e., caused by post-ganglionic noradrenergic denervation of the heart and blood vessels [9], but hypovolemia and drugs with BP lowering effect may also cause $\mathrm{OH}$ of non-neurogenic origin. 
Meals can worsen $\mathrm{OH}$ by inducing excessive blood pooling in the splanchnic bed, a phenomenon called postprandial hypotension. Other exacerbating factors include heat exposure, fever, anemia, prolonged bed rest, hyperventilation, alcohol intake and physical exercise. In this case, the BP starts falling already while exercising, but patients typically experience syncope or presyncope soon after its cessation.

In about $50 \%$ of patients with neurogenic $\mathrm{OH}$, baroreflex dysfunction and other, to date, not fully understood mechanisms, may cause hypertension in the supine position, which can be severe and last for several hours during nocturnal sleep $[10,11]$.

Identifying and managing $\mathrm{OH}$ is important, because it impacts on activity of daily living and increases the risk of injurious falls [12]. Supine hypertension ( $\mathrm{SH})$ is generally asymptomatic, but it may limit an effective treatment of $\mathrm{OH}$, worsen it by fostering pressure natriuresis overnight and pose patients at higher risk of hypertensive emergencies [13]. In the long term, the combination of very low and very high BP values may also cause end-organ damage at cardiac, renal and cerebral level [14-16].

Here we provide a practical guide on how to screen, diagnose and treat $\mathrm{OH}$ in patients with $\mathrm{PD}$, by taking into account supine and nocturnal hypertension. A similar approach can be adopted in patients with multiple system atrophy, an atypical parkinsonian disorder characterized by early, severe $\mathrm{OH}$ [17], poorly L-Dopa responsive parkinsonism, cerebellar ataxia and pyramidal signs in various combinations [18].

\section{FIRST STEP: MAKE THE RIGHT DIAGNOSIS}

Given its unspecific, and sometimes asymptomatic, presentation, $\mathrm{OH}$ should be actively screened at bedside by measuring the $\mathrm{BP}$ and heart rate (HR) supine and after 3 minutes upon standing [19]. OH is diagnosed in case of a systolic BP fall $\geq 20 \mathrm{mmHg}$ and/or diastolic $\geq 10 \mathrm{mmHg}$ with respect to baseline [20]. Standing systolic BP values $<90 \mathrm{mmHg}$ are also highly suggestive of $\mathrm{OH}$ and often predict symptoms of orthostatic intolerance [7, 21]. In case of milder BP falls at the 3rd minute upon standing, it is recommendable to prolong the orthostatic challenge to 5-10 minutes, in order to screen for delayed $\mathrm{OH}$, a possible precursor of classic $\mathrm{OH}[22]$.

Once a diagnosis of $\mathrm{OH}$ is established, nonneurogenic causes and exacerbating factors, such as dehydration, anemia or infections should be ruled out. The medication schedule should be also reviewed for drugs with BP lowering effect, which may have been recently introduced or increased in dose: not only anti-hypertensive agents, but also dopaminergic drugs, tricyclics, opioids, neuroleptics or $\alpha$-blockers.

Cardiovascular autonomic function tests ultimately distinguish neurogenic from non-neurogenic $\mathrm{OH}$. In non-neurogenic OH, HR increases markedly upon standing, trying to counteract the fall in BP. By contrast, in neurogenic $\mathrm{OH}$, no or only small orthostatic HR rises are observed despite severe BP falls, because of insufficient baroreflex stimulation (see Fig. 1). An increase in $\mathrm{HR}<0.5$ beats-perminute/mmHg of systolic BP fall after 3 minutes of head-up tilt indicates neurogenic $\mathrm{OH}$ with high diagnostic accuracy [23]. Patients with neurogenic $\mathrm{OH}$ also miss the physiological BP overshoot at the end of a Valsalva maneuver, indicating an insufficient noradrenergic stimulation to the blood vessels (see Fig. 1) [11]. Performing a standing test under continuous BP monitoring may help identifying initial $\mathrm{OH}$, a transient form of $\mathrm{OH}$, which may also cause orthostatic intolerance [21].

All patients newly diagnosed with neurogenic $\mathrm{OH}$ should be screened for SH with in-office supine BP measurements [13]. Validated questionnaires, such as the Orthostatic Hypotension Questionnaire [24], and home BP measurements (see template in Fig. 2) provide useful additional information on the severity of $\mathrm{OH}$ in daily life and monitor for post-prandial hypotension and $\mathrm{SH}$. If suspected, nocturnal hypertension is diagnosed with a $24 \mathrm{~h}$-ambulatory $\mathrm{BP}$ monitoring.

\section{TREATMENT OF OH}

\section{Correct non-neurogenic causes of $\mathrm{OH}$ and exacerbating factors}

If the clinical assessment pinpoints dehydration, severe anemia or infections, these should be treated first.

When the onset of $\mathrm{OH}$ can be put in temporal relationship with the introduction or increase in dosage of any BP lowering drug, such therapeutic regimen should be carefully reconsidered after a case-by-case risk/benefit evaluation. In clinical practice, exacerbation of $\mathrm{OH}$ may occur during the titration of dopamine agonists [25, 26] and, less frequently, of L-Dopa [27, $28]$ due to vasodilatory effects and increased renal water and salt excretion $[29,30]$. While, in some 


\section{DIAGNOSIS}
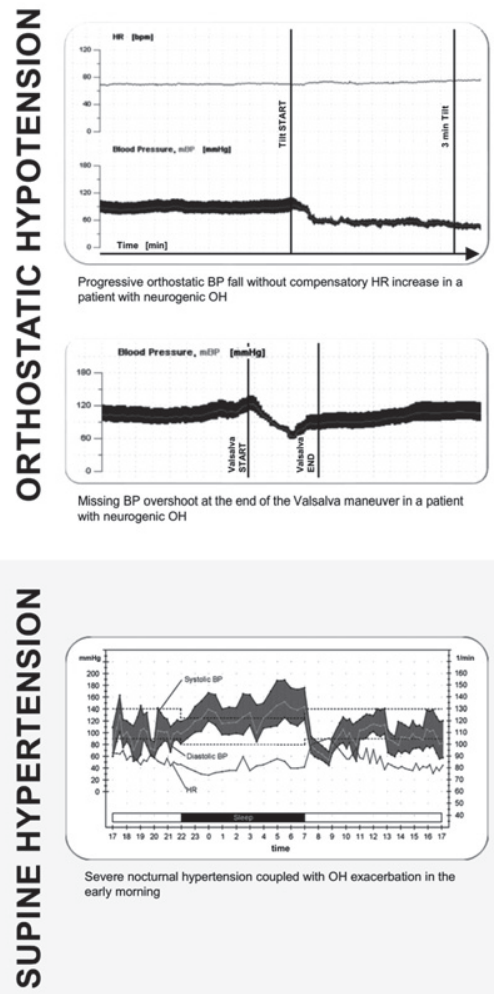

OH: systolic BP fall $\geq 20 \mathrm{mmHg}$ or diastolic $\geq 10 \mathrm{mmHg}$ within 3 minutes of standing or head-up tilt

Delayed $\mathrm{OH}$ : $\mathrm{OH}$ developing after 3 minutes of standing or head-up tilt

Initial OH: systolic BP fall $\geq 40 \mathrm{mmHg}$ or diastolic $\geq 20$ $\mathrm{mmHg}$ within 15 seconds upon standing with recovery $\mathrm{mmHg}$ within 15
within 30 seconds

Exclude non-neurogenic causes of $\mathrm{OH}$ and exacerbating factors

- Dehydration

Recent introduction or increase in dosage of drugs with BP lowering effect

- Severe anemia

- Infections

Neurogenic $\mathrm{OH}$ at autonomic function testing - Blunted orthostatic HR increase $\Delta \frac{\mathrm{HR}}{\mathrm{BP}} \leq 0.5$ after 3 minutes of head-up tilt - Missing BP overshoot at the end of Valsalva maneuver

\section{DIAGNOSIS}

SH: Systolic BP $\geq 140 \mathrm{mmHg}$ and/or diastolic $\geq 90 \mathrm{mmHg}$, measured after $5 \mathrm{~min}$ of rest in the supine position

\begin{tabular}{l|c|c} 
Severity degree & $\begin{array}{c}\text { Systolic BP } \\
{[\mathrm{mmHg}]}\end{array}$ & $\begin{array}{c}\text { Diastolic BP } \\
{[\mathrm{mmHg}]}\end{array}$ \\
\hline Mild & $140-159$ & $90-99$ \\
Moderate & $160-179$ & $100-109$ \\
Severe & $\geq 180$ & $\geq 110$
\end{tabular}

Nocturnal Hypertension

Two pathologic BP profiles:

- Reduced dipping: mean nocturnal BP reduction of $<10 \%$ with respect to daytime

Non-dipping or rising: BP does not decrease or even increases over night with respect to daytime
TREATMENT

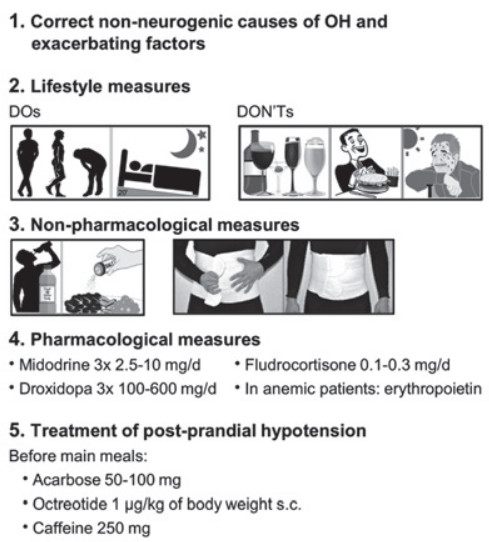

TREATMENT

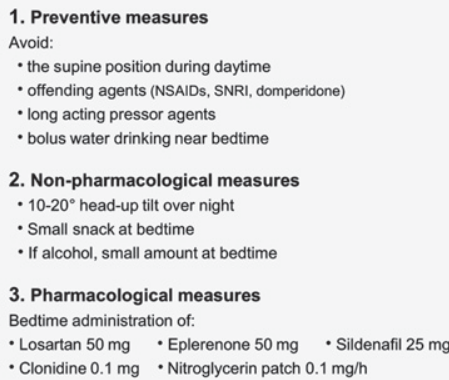

1. Preventive measures

Avoid:

- the supine position during daytime

- offending agents (NSAIDs, SNRI, domperidone)

- long acting pressor agents

- bolus water drinking near bedtime

2. Non-pharmacological measures

- 10-20 $0^{\circ}$ head-up tilt over night

- Small snack at bedtime

- If alcohol, small amount at bedtime

3. Pharmacological measures

Bedtime administration of:

- Losartan $50 \mathrm{mg}$ - Eplerenone $50 \mathrm{mg}$ - Sildenafil $25 \mathrm{mg}$

- Clonidine $0.1 \mathrm{mg}$ • Nitroglycerin patch $0.1 \mathrm{mg} / \mathrm{h}$

Fig. 1. Management of orthostatic hypotension and supine hypertension in Parkinson's disease. OH, orthostatic hypotension; BP, blood pressure; HR, heart rate; NSAIDs, non-steroidal anti-inflammatory drugs; SNRI, serotonin-noradrenaline reuptake inhibitors. Adapted from Fanciulli et al. 2014 [11] and Fanciulli et al., 2016 [37] with permission from Springer and John Wiley and Sons.

patients, orthostatic intolerance may ameliorate without intervention at follow-up, in others $\mathrm{OH}$-specific measures may be necessary to maintain an adequate dopaminergic regimen.

\section{Lifestyle measures}

If no reversible cause of $\mathrm{OH}$ can be identified, or if symptoms of $\mathrm{OH}$ persist despite potentially exacerbating factors have been removed, lifestyle, non-pharmacological and pharmacological measures should be applied stepwise depending on the severity of $\mathrm{OH}$ symptoms [31].

Patients with $\mathrm{OH}$ should be carefully educated to:

- stand up slowly, especially after resting supine for longer times; in this case, patients may pause in the sitting position before standing up;

- avoid heat exposure, prolonged standing, alcohol, large, carbohydrate-rich meals and Valsalva-like maneuvers during micturition or bowel movements. Daily routine adaptations, like showering on a chair or (for male patients) voiding in the seated position may be required;

- in case of dizziness and inability to sit or lie down, perform BP rising maneuvers such as stepping on the place, crossing the legs, tense the gluteal and abdominal muscles, bending forward or clenching the fists. A training session under continuous BP monitoring may help instructing the patient how to perform these maneuvers properly and selecting the most efficacious one [32];

- sleep in a $10-20^{\circ}$ full-body head-up tilt position in order to stimulate the overnight production of antidiuretic hormone and reduce pressure natriuresis [33].

\section{Non-pharmacological measures}

Increasing water (up to $2,51 /$ day) and salt (6-10 g/day) intake represents a key nonpharmacological measure to combat $\mathrm{OH}$ [34]. Drinking a bolus of water of $500 \mathrm{ml}$ significantly 


\section{Home blood pressure diary}

\begin{tabular}{|c|c|c|c|c|c|c|c|c|c|c|c|c|c|c|}
\hline Name: & & & \multicolumn{4}{|c|}{ Date of birth: } & \multicolumn{8}{|c|}{$\begin{array}{l}\text { height: } \ldots \ldots \ldots . \quad \mathrm{cm} \\
\text { weight: } \ldots \ldots \ldots . . . . \mathrm{kg}\end{array}$} \\
\hline \multirow[t]{2}{*}{ Date } & \multirow{2}{*}{$\begin{array}{l}\text { Fluid intake } \\
\text { (liters) }\end{array}$} & \multirow[t]{2}{*}{ Measurements } & \multicolumn{3}{|c|}{$\begin{array}{l}\text { In the morning } \\
\text { (before breakfast) }\end{array}$} & \multirow{2}{*}{ 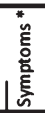 } & \multirow{2}{*}{ systolic } & \multirow{2}{*}{$\begin{array}{l}\text { After lunch } \\
\text { diastolic }\end{array}$} & \multirow{2}{*}{$\mathrm{HR}$} & \multirow{2}{*}{ 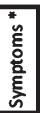 } & \multicolumn{3}{|c|}{$\begin{array}{l}\text { In the evening } \\
\text { (before going to bed) }\end{array}$} & \multirow{2}{*}{ है } \\
\hline & & & systolic & diastolic & HR & & & & & & systolic & diastolic & $\mathrm{HR}$ & \\
\hline \multirow{2}{*}{$\ldots$} & \multirow{2}{*}{-1} & $5^{\prime}$ min supine & & & & & & & & & & & & \\
\hline & & $3^{\prime}$ min standing & & & & & & & & & & & & \\
\hline \multirow{2}{*}{$\ldots \ldots \ldots \ldots \ldots$} & \multirow{2}{*}{-1} & $5^{\prime}$ min supine & & & & & & & & & & & & \\
\hline & & $3^{\prime}$ min standing & & & & & & & & & & & & \\
\hline \multirow{2}{*}{$\ldots \ldots \ldots \ldots \ldots \ldots \ldots$} & \multirow{2}{*}{-1} & $5^{\prime}$ min supine & & & & & & & & & & & & \\
\hline & & $3^{\prime}$ min standing & & & & & & & & & & & & \\
\hline \multirow{2}{*}{$\ldots$} & \multirow{2}{*}{-1} & $5^{\prime}$ min supine & & & & & & & & & & & & \\
\hline & & $3^{\prime}$ min standing & & & & & & & & & & & & \\
\hline \multirow{2}{*}{$\ldots \ldots \ldots \ldots \ldots \ldots$} & \multirow{2}{*}{-1} & $5^{\prime}$ min supine & & & & & & & & & & & & \\
\hline & & $3^{\prime}$ min standing & & & & & & & & & & & & \\
\hline \multirow{4}{*}{ 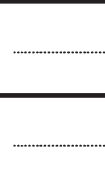 } & \multirow{2}{*}{-1} & $5^{\prime}$ min supine & & & & & & & & & & & & \\
\hline & & $3^{\prime}$ min standing & & & & & & & & & & & & \\
\hline & \multirow{2}{*}{-1} & $5^{\prime}$ min supine & & & & & & & & & & & & \\
\hline & & $3^{\prime}$ min standing & & & & & & & & & & & & \\
\hline
\end{tabular}

Fig. 2. Template of a home blood pressure diary for patients with orthostatic hypotension.

raises the $\mathrm{BP}$ in the following 30 to 90 minutes [35]: patients with $\mathrm{OH}$ may take advantage of such pressor effect by scheduling water intake on the basis of planned activities. Caution in water and salt supplementation should be used in patients with known heart, kidney or liver failure.

Abdominal binders also ameliorate $\mathrm{OH}$ by reducing the splanchnic venous pooling [36, 37], while compression stockings did not prove effective [34, 38] and may be difficult for elderly patients to put on.

\section{Pharmacological measures}

If non-pharmacological interventions provide insufficient control of $\mathrm{OH}$ symptoms, pharmacological measures should be implemented. One strategy is to increase the vascular tone with sympathomimetic agents, another is to expand the circulating blood volume, either by increasing the plasma volume or the red cell mass.

The choice of the pressor agent should be based on expected benefits, relevant comorbidities and potential adverse effects. If $\mathrm{OH}$ is the main cause of disability, higher dosages could be pursued in order to warrant good orthostatic tolerance during activities of daily living, while in patients, who are wheel- chair bound due to advanced parkinsonism, avoiding polypharmacy and potential side effects may be more important.

Midodrine is a direct $\alpha_{1}$-adrenoceptor agonist [39-41], whereas droxidopa is a noradrenaline precursor that is converted into noradrenaline by the dopa-decarboxylase [42-45]. Both sympathomimetic agents are started at the lowest dose 3 times/day and increased gradually depending on the severity of $\mathrm{OH}$ symptoms (see Fig. 1). Patients with known cardiac disease, kidney failure or urinary retention shouldn't receive sympathomimetic agents.

Fludrocortisone is a synthetic mineralocorticoid that increases plasma volume by inducing sodium retention. It is used either in monotherapy or in combination with midodrine, but no studies compared the efficacy and safety of single versus combined drug regimens in the long term yet [34]. Fludrocortisone is contraindicated in patients with heart or kidney failure and electrolyte monitoring is recommended to exclude hypokalemia, especially in case of fever or diarrhea.

Erythropoietin, combined with iron supplements, may have a positive effect on $\mathrm{OH}$ in patients with concurrent anemia, but the risk of polycythemia and thrombotic complications must be considered [46]. 
To date, only elastic abdominal binders and droxidopa specifically proved effective and safe in treating PD-related $\mathrm{OH}$ in the short term [34, 47]. Recent observational studies report positive midterm effects of droxidopa [48] and long-term studies are ongoing, but droxidopa is not licensed in Europe at the moment.

For pyridostigmine, yohimbine, ergotamine, dihydroergotamine, ephedrine, desmopressin, indomethacin and fluoxetine, there are case reports and proof of concepts studies reporting on their efficacy on $\mathrm{OH}$, but the safety profile is unclear to date [34]. Such pharmacological options can be considered in selected cases with refractory $\mathrm{OH}$, if other agents proved ineffective or caused side effects.

\section{TREATMENT OF POST-PRANDIAL HYPOTENSION}

Conservative measures to treat postprandial hypotension include alcohol abstinence and fractionating meals.

If conservative measures prove ineffective, acarbose, an anti-diabetic agent that inhibits the intestinal $\alpha$-glucosidase, can be used in selected cases [49] (see Fig. 1). Alternatively, subcutaneous octreotide, a somatostatin analogue, may be helpful [34], except for diabetic patients due to increased risk of postprandial hyperglycemic crisis.

Controversial evidence is available for caffeine: while low doses $(250 \mathrm{mg})$ before meals may positively impact on postprandial hypotension [50], higher dosages have diuretic effects, which may worsen $\mathrm{OH}$ [51].

\section{TREATMENT OF SUPINE AND NOCTURNAL HYPERTENSION}

\section{Preventive measures}

Simple behavioral measures may prevent patients with neurogenic $\mathrm{OH}$ from developing overt $\mathrm{SH}$ [52]:

- Patients should avoid the supine position during daytime, when pressor agents are scheduled. If wished, a semi-seated position is recommendable for daytime naps;

- In patients who need pressor agents to control $\mathrm{OH}$ symptoms, short-acting drugs (e.g. midodrine or droxidopa) should be preferred over long-acting ones (e.g. fludrocortisone) and their last administration should be scheduled no later than $4 \mathrm{pm}$. This may be even reduced or stopped, if $\mathrm{OH}$ symptoms are less severe in the second half of the day;

- Drugs, which are not primarily used as pressor agents, but which can cause significant BP increases in patients with baroreflex dysfunction should be avoided (e.g., NSAIDs, domperidone or SNRI);

- Bolus water drinking should be avoided in the 30 to 90 minutes before night sleep, because of the abovementioned pressor effect.

\section{Non-pharmacological and pharmacological measures}

When SH is present, non-pharmacological and pharmacological measures should be introduced gradually based on SH severity degree, especially overnight (see Fig. 1).

Treating nocturnal hypertension aims at reducing the risk of hypertensive emergencies, plasma volume loss overnight (with possible reduction of $\mathrm{OH}$ severity the day after) and end-organ damage in the long term. These potential benefits must be weighed against the risks of worsening $\mathrm{OH}$ and increasing the risk of syncope and falls. The highest and lowest BP levels observed at home or $24 \mathrm{~h}$ ambulatory BP monitoring may help estimating the risk of both hypertensive emergencies and of syncope in single patients.

Non-pharmacological measures can be sought to treat milder forms of nocturnal hypertension:

- 10-20 full-body head-up tilt during sleep;

- A small snack before bedtime to counteract SH by causing post-prandial hypotension. Following the same principle, enteral nutrition can be scheduled at nighttime in patients who are fed per gastrostomy;

- While the use of alcohol is not recommended to treat $\mathrm{SH}$, patients who wish to enjoy small amounts of alcoholic beverages should do this before bedtime.

Pharmacological interventions may be considered in patients in whom BP values overnight remain high despite preventive and non-pharmacological measures. Few studies addressed the pharmacological treatment of nocturnal hypertension in patients with neurogenic $\mathrm{OH}$. Bedtime administration of eplerenone [53], losartan [54], sildenafil [55], clonidine [56], transdermal nitroglycerin [57], and nifedipine [58] reduced systolic BP overnight. 
Losartan, an angiotensin II-receptor antagonist, and clonidine, a CNS-active sympatholytic drug, also diminished nocturnal sodium excretion, while nifedipine worsened $\mathrm{OH}$ symptoms the day after due to its long half-life. Drugs to treat SH should therefore be short-acting and scheduled in the evening, while during daytime an effective treatment of $\mathrm{OH}$ should be prioritized.

\section{FUTURE PERSPECTIVES}

Despite combined treatment strategies, the symptomatic burden of $\mathrm{OH}$ remains high in a significant proportion of patients with PD and BP fluctuations due to concomitant SH represent a management challenge. This highlights the need for new therapeutic and safety studies in PD.

Supine plasma noradrenaline levels, which are generated from the spillover of post-ganglionic noradrenergic synapses, may guide an individualized choice of the pressor agent to combat $\mathrm{OH}$. Low supine plasma noradrenaline levels may predict a better response to droxidopa [59]. On the other hand, higher supine plasma noradrenaline levels indicate dysfunctional, but preserved noradrenergic fibers and may provide the pharmacological rationale for treating $\mathrm{OH}$ with noradrenaline transporter blockers, which academic and industry-driven studies are currently investigating in PD and other autonomic disorders. These and other strategies will hopefully help optimizing the management of disorders of BP regulation in PD.

\section{ACKNOWLEDGMENTS}

This is an academic study without external financial support. Dr. Leys is supported by a research grant of the Stichting ParkinsonFond.

\section{CONFLICT OF INTEREST}

The authors have no conflict of interest to report.

\section{Full financial disclosures for the last 12 months}

Alessandra Fanciulli: Dr. Fanciulli reports royalties from Springer Nature Publishing Group, speaker fees and honoraria from the Austrian Autonomic Society, Austrian Parkinson Society, Ordensklinikum Linz, International Parkinson Disease and Movement Disorders Society and Theravance Biopharma and research grants from the Stichting ParkinsonFond and the Österreichischer Austausch Dienst, outside of the submitted work.

Fabian Leys: Dr. Leys reports no disclosures.

Cristian Falup-Pecurariu: Dr. Falup-Pecurariu reports royalties from Springer Nature Publishing Group, speaker fees and honoraria from the International Parkinson and Movement Disorders Society, outside of the submitted work.

Roland Thijs: Dr. Thijs reports speaker fees from Novartis, consultancy fees from Theravance Biopharma and research support from the Dutch Epilepsy Foundation Dutch, the Netherlands Organization for Health Research and Development (ZonMW) and De Christelijke Vereniging voor de Verpleging van Lijders aan Epilepsie, outside of the submitted work.

Gregor K. Wenning: Dr. Wenning reports consultancy fees from Biogen, Biohaven, Lundbeck, Minoryx, Takeda, Theravance and research support from the Austrian Science Fund, International Parkinson Disease and Movement Disorders Society and the Medical University Innsbruck, outside of the submitted work.

\section{REFERENCES}

[1] Velseboer DC, de Haan RJ, Wieling W, Goldstein DS, de Bie RM (2011) Prevalence of orthostatic hypotension in Parkinson's disease: A systematic review and meta-analysis. Parkinsonism Relat Disord 17, 724-729.

[2] Milazzo V, Di Stefano C, Servo S, Zibetti M, Lopiano L, Maule S (2012) Neurogenic orthostatic hypotension as the initial feature of Parkinson disease. Clin Auton Res 22, 203206.

[3] Kaufmann H, Norcliffe-Kaufmann L, Palma JA, Biaggioni I, Low PA, Singer W, Goldstein DS, Peltier AC, Shibao CA, Gibbons CH, Freeman R, Robertson D (2017) Natural history of pure autonomic failure: A United States prospective cohort. Ann Neurol 81, 287-297.

[4] Singer W, Berini SE, Sandroni P, Fealey RD, Coon EA, Suarez MD, Benarroch EE, Low PA (2017) Pure autonomic failure: Predictors of conversion to clinical CNS involvement. Neurology 88, 1129-1136.

[5] Giannini G, Calandra-Buonaura G, Asioli GM, Cecere A, Barletta G, Mignani F, Ratti S, Guaraldi P, Provini F, Cortelli $P(2018)$ The natural history of idiopathic autonomic failure: The IAF-BO cohort study. Neurology 91, e1245-e1254.

[6] Freeman R (2008) Clinical practice. Neurogenic orthostatic hypotension. N Engl J Med 358, 615-624.

[7] Palma JA, Gomez-Esteban JC, Norcliffe-Kaufmann L, Martinez J, Tijero B, Berganzo K, Kaufmann H (2015) Orthostatic hypotension in Parkinson disease: How much you fall or how low you go? Mov Disord 30, 639-645.

[8] Indelicato E, Fanciulli A, Poewe W, Antonini A, Pontieri FE, Wenning GK (2015) Cerebral autoregulation and white matter lesions in Parkinson's disease and multiple system atrophy. Parkinsonism Relat Disord 21, 1393-1397. 
[9] Kaufmann H, Norcliffe-Kaufmann L, Palma JA (2020) Baroreflex dysfunction. N Engl J Med 382, 163-178.

[10] Fanciulli A, Gobel G, Ndayisaba JP, Granata R, Duerr S, Strano S, Colosimo C, Poewe W, Pontieri FE, Wenning GK (2016) Supine hypertension in Parkinson's disease and multiple system atrophy. Clin Auton Res 26, 97-105.

[11] Fanciulli A, Strano S, Ndayisaba JP, Goebel G, Gioffre L, Rizzo M, Colosimo C, Caltagirone C, Poewe W, Wenning GK, Pontieri FE (2014) Detecting nocturnal hypertension in Parkinson's disease and multiple system atrophy: Proposal of a decision-support algorithm. J Neurol 261, 1291-1299.

[12] Romagnolo A, Zibetti M, Merola A, Canova D, Sarchioto M, Montanaro E, Artusi CA, Vallelonga F, Maule S, Lopiano L (2019) Cardiovascular autonomic neuropathy and falls in Parkinson disease: A prospective cohort study. J Neurol 266, 85-91.

[13] Fanciulli A, Jordan J, Biaggioni I, Calandra-Buonaura G, Cheshire WP, Cortelli P, Eschlboeck S, Grassi G, Hilz MJ, Kaufmann H, Lahrmann H, Mancia G, Mayer G, NorcliffeKaufmann L, Pavy-Le Traon A, Raj SR, Robertson D, Rocha I, Struhal W, Thijs R, Tsioufis KP, van Dijk JG, Wenning GK (2018) Consensus statement on the definition of neurogenic supine hypertension in cardiovascular autonomic failure by the American Autonomic Society (AAS) and the European Federation of Autonomic Societies (EFAS): Endorsed by the European Academy of Neurology (EAN) and the European Society of Hypertension (ESH). Clin Auton Res 28, 355-362.

[14] Fanciulli A, Strano S, Colosimo C, Caltagirone C, Spalletta G, Pontieri FE (2013) The potential prognostic role of cardiovascular autonomic failure in alpha-synucleinopathies. Eur J Neurol 20, 231-235.

[15] Rothwell PM (2010) Limitations of the usual blood-pressure hypothesis and importance of variability, instability, and episodic hypertension. Lancet 375, 938-948.

[16] Ten Harmsen BL, van Rumund A, Aerts MB, Bergkamp MI, Esselink RAJ, Richard E, Meijer FJA, Bloem BR, van Wamelen DJ (2018) Clinical correlates of cerebral white matter abnormalities in patients with Parkinson's disease. Parkinsonism Relat Disord 49, 28-33.

[17] Fanciulli A, Goebel G, Lazzeri G, Scherfler C, Gizewski ER, Granata R, Kiss G, Strano S, Colosimo C, Pontieri FE, Kaufmann H, Seppi K, Poewe W, Wenning GK (2019) Early distinction of Parkinson-variant multiple system atrophy from Parkinson's disease. Mov Disord 34, 440-441.

[18] Fanciulli A, Wenning GK (2015) Multiple-system atrophy. N Engl J Med 372, 249-263.

[19] Fanciulli A, Campese N, Wenning GK (2019) The Schellong test: Detecting orthostatic blood pressure and heart rate changes in German-speaking countries. Clin Auton Res 29, 363-366.

[20] Freeman R, Wieling W, Axelrod FB, Benditt DG, Benarroch E, Biaggioni I, Cheshire WP, Chelimsky T, Cortelli P, Gibbons CH, Goldstein DS, Hainsworth R, Hilz MJ, Jacob G, Kaufmann H, Jordan J, Lipsitz LA, Levine BD, Low PA, Mathias C, Raj SR, Robertson D, Sandroni P, Schatz I, Schondorff R, Stewart JM, van Dijk JG (2011) Consensus statement on the definition of orthostatic hypotension, neurally mediated syncope and the postural tachycardia syndrome. Clin Auton Res 21, 69-72.

[21] Brignole M, Moya A, de Lange FJ, Deharo JC, Elliott PM, Fanciulli A, Fedorowski A, Furlan R, Kenny RA, Martin A, Probst V, Reed MJ, Rice CP, Sutton R, Ungar A, van Dijk JG, ESC Scientific Document Group (2018) 2018 ESC
Guidelines for the diagnosis and management of syncope. Eur Heart J 39, 1883-1948.

[22] Gibbons CH, Freeman R (2015) Clinical implications of delayed orthostatic hypotension: A 10-year follow-up study. Neurology 85, 1362-1367.

[23] Norcliffe-Kaufmann L, Kaufmann H, Palma JA, Shibao CA, Biaggioni I, Peltier AC, Singer W, Low PA, Goldstein DS, Gibbons CH, Freeman R, Robertson D (2018) Orthostatic heart rate changes in patients with autonomic failure caused by neurodegenerative synucleinopathies. Ann Neurol 83, $522-531$.

[24] Kaufmann H, Malamut R, Norcliffe-Kaufmann L, Rosa K, Freeman R (2012) The Orthostatic Hypotension Questionnaire (OHQ): Validation of a novel symptom assessment scale. Clin Auton Res 22, 79-90.

[25] Kujawa K, Leurgans S, Raman R, Blasucci L, Goetz CG (2000) Acute orthostatic hypotension when starting dopamine agonists in Parkinson's disease. Arch Neurol 57, 1461-1463.

[26] Lang AE (2001) Acute orthostatic hypotension when starting dopamine agonist therapy in parkinson disease: The role of domperidone therapy. Arch Neurol 58, 835.

[27] Jost WH, Altmann C, Fiesel T, Becht B, Ringwald S, Hoppe $\mathrm{T}$ (2020) Influence of levodopa on orthostatic hypotension in Parkinson's disease. Neurol Neurochir Pol 54, 200-203.

[28] Mehagnoul-Schipper DJ, Boerman RH, Hoefnagels WH, Jansen RW (2001) Effect of levodopa on orthostatic and postprandial hypotension in elderly Parkinsonian patients. J Gerontol A Biol Sci Med Sci 56, M749-755.

[29] Harris RC, Zhang MZ (2012) Dopamine, the kidney, and hypertension. Curr Hypertens Rep 14, 138-143.

[30] Missale C, Nash SR, Robinson SW, Jaber M, Caron MG (1998) Dopamine receptors: From structure to function. Physiol Rev 78, 189-225.

[31] Gibbons CH, Schmidt P, Biaggioni I, Frazier-Mills C, Freeman R, Isaacson S, Karabin B, Kuritzky L, Lew M, Low P, Mehdirad A, Raj SR, Vernino S, Kaufmann H (2017) The recommendations of a consensus panel for the screening, diagnosis, and treatment of neurogenic orthostatic hypotension and associated supine hypertension. J Neurol 264, $1567-1582$.

[32] Wieling W, van Dijk N, Thijs RD, de Lange FJ, Krediet CT, Halliwill JR (2015) Physical countermeasures to increase orthostatic tolerance. J Intern Med 277, 69-82.

[33] Ten Harkel AD, Van Lieshout JJ, Wieling W (1992) Treatment of orthostatic hypotension with sleeping in the head-up tilt position, alone and in combination with fludrocortisone. J Intern Med 232, 139-145.

[34] Eschlbock S, Wenning G, Fanciulli A (2017) Evidencebased treatment of neurogenic orthostatic hypotension and related symptoms. J Neural Transm (Vienna) 124, 15671605 .

[35] Schroeder C, Bush VE, Norcliffe LJ, Luft FC, Tank J, Jordan J, Hainsworth R (2002) Water drinking acutely improves orthostatic tolerance in healthy subjects. Circulation 106, 2806-2811.

[36] Okamoto LE, Diedrich A, Baudenbacher FJ, Harder R, Whitfield JS, Iqbal F, Gamboa A, Shibao CA, Black BK, Raj SR, Robertson D, Biaggioni I (2016) Efficacy of servocontrolled splanchnic venous compression in the treatment of orthostatic hypotension: A randomized comparison with midodrine. Hypertension 68, 418-426.

[37] Fanciulli A, Goebel G, Metzler B, Sprenger F, Poewe W, Wenning GK, Seppi K (2016) Elastic abdominal binders 
attenuate orthostatic hypotension in Parkinson's disease. Mov Disord Clin Pract 3, 156-160.

[38] Newton JL, Frith J (2018) The efficacy of nonpharmacologic intervention for orthostatic hypotension associated with aging. Neurology 91, e652-e656.

[39] Wright RA, Kaufmann HC, Perera R, Opfer-Gehrking TL, McElligott MA, Sheng KN, Low PA (1998) A double-blind, dose-response study of midodrine in neurogenic orthostatic hypotension. Neurology 51, 120-124.

[40] Jankovic J, Gilden JL, Hiner BC, Kaufmann H, Brown DC, Coghlan CH, Rubin M, Fouad-Tarazi FM (1993) Neurogenic orthostatic hypotension: A double-blind, placebo-controlled study with midodrine. Am J Med 95, 38-48.

[41] Low PA, Gilden JL, Freeman R, Sheng KN, McElligott MA (1997) Efficacy of midodrine vs placebo in neurogenic orthostatic hypotension. A randomized, double-blind multicenter study. Midodrine Study Group. JAMA 277, 1046-1051.

[42] Freeman R, Landsberg L, Young J (1999) The treatment of neurogenic orthostatic hypotension with 3,4-DL-threodihydroxyphenylserine: A randomized, placebo-controlled, crossover trial. Neurology 53, 2151-2157.

[43] Kaufmann H, Saadia D, Voustianiouk A, Goldstein DS, Holmes C, Yahr MD, Nardin R, Freeman R (2003) Norepinephrine precursor therapy in neurogenic orthostatic hypotension. Circulation 108, 724-728.

[44] Kaufmann H, Freeman R, Biaggioni I, Low P, Pedder S, Hewitt LA, Mauney J, Feirtag M, Mathias CJ (2014) Droxidopa for neurogenic orthostatic hypotension: A randomized, placebo-controlled, phase 3 trial. Neurology 83, 328-335.

[45] Hauser RA, Isaacson S, Lisk JP, Hewitt LA, Rowse G (2015) Droxidopa for the short-term treatment of symptomatic neurogenic orthostatic hypotension in Parkinson's disease (nOH306B). Mov Disord 30, 646-654.

[46] Perera R, Isola L, Kaufmann H (1995) Effect of recombinant erythropoietin on anemia and orthostatic hypotension in primary autonomic failure. Clin Auton Res 5, 211-213.

[47] Seppi K, Ray Chaudhuri K, Coelho M, Fox SH, Katzenschlager R, Perez Lloret S, Weintraub D, Sampaio C, the collaborators of the Parkinson's Disease Update on NonMotor Symptoms Study Group on behalf of the Movement Disorders Society Evidence-Based Medicine Committee (2019) Update on treatments for nonmotor symptoms of Parkinson's disease-an evidence-based medicine review. Mov Disord 34, 180-198.

[48] Francois C, Shibao CA, Biaggioni I, Duhig AM, McLeod K, Ogbonnaya A, Quillen A, Cannon J, Padilla B, Yue B, Orloski L, Kymes SM (2019) Six-month use of droxidopa for neurogenic orthostatic hypotension. Mov Disord Clin Pract 6, 235-242.

[49] Shibao C, Gamboa A, Diedrich A, Dossett C, Choi L, Farley G, Biaggioni I (2007) Acarbose, an alpha-glucosidase inhibitor, attenuates postprandial hypotension in autonomic failure. Hypertension 50, 54-61.
[50] Onrot J, Goldberg MR, Biaggioni I, Hollister AS, Kingaid D, Robertson D (1985) Hemodynamic and humoral effects of caffeine in autonomic failure. Therapeutic implications for postprandial hypotension. $N$ Engl J Med 313, 549-554.

[51] Seal AD, Bardis CN, Gavrieli A, Grigorakis P, Adams JD, Arnaoutis G, Yannakoulia M, Kavouras SA (2017) Coffee with high but not low caffeine content augments fluid and electrolyte excretion at rest. Front Nutr 4, 40.

[52] Jordan J, Fanciulli A, Tank J, Calandra-Buonaura G, Cheshire WP, Cortelli P, Eschlboeck S, Grassi G, Hilz MJ, Kaufmann H, Lahrmann H, Mancia G, Mayer G, NorcliffeKaufmann L, Pavy-Le Traon A, Raj SR, Robertson D, Rocha I, Reuter H, Struhal W, Thijs RD, Tsioufis KP, Gert van Dijk J, Wenning GK, Biaggioni I (2019) Management of supine hypertension in patients with neurogenic orthostatic hypotension: Scientific statement of the American Autonomic Society, European Federation of Autonomic Societies, and the European Society of Hypertension. $J$ Hypertens 37, 1541-1546.

[53] Arnold AC, Okamoto LE, Gamboa A, Black BK, Raj SR, Elijovich F, Robertson D, Shibao CA, Biaggioni I (2016) Mineralocorticoid receptor activation contributes to the supine hypertension of autonomic failure. Hypertension $\mathbf{6 7}$, 424-429.

[54] Arnold AC, Okamoto LE, Gamboa A, Shibao C, Raj SR, Robertson D, Biaggioni I (2013) Angiotensin II, independent of plasma renin activity, contributes to the hypertension of autonomic failure. Hypertension 61, 701-706.

[55] Gamboa A, Shibao C, Diedrich A, Paranjape SY, Farley G, Christman B, Raj SR, Robertson D, Biaggioni I (2008) Excessive nitric oxide function and blood pressure regulation in patients with autonomic failure. Hypertension 51, 1531-1536.

[56] Shibao C, Gamboa A, Abraham R, Raj SR, Diedrich A, Black B, Robertson D, Biaggioni I (2006) Clonidine for the treatment of supine hypertension and pressure natriuresis in autonomic failure. Hypertension 47, 522-526.

[57] Shibao C, Gamboa A, Diedrich A, Biaggioni I (2006) Management of hypertension in the setting of autonomic dysfunction. Curr Treat Options Cardiovasc Med 8, 105109.

[58] Jordan J, Shannon JR, Pohar B, Paranjape SY, Robertson D, Robertson RM, Biaggioni I (1999) Contrasting effects of vasodilators on blood pressure and sodium balance in the hypertension of autonomic failure. J Am Soc Nephrol 10, 35-42.

[59] Palma JA, Norcliffe-Kaufmann L, Martinez J, Kaufmann H (2018) Supine plasma NE predicts the pressor response to droxidopa in neurogenic orthostatic hypotension. Neurology 91, e1539-e1544. 